\title{
Escala de Significado do Dinheiro: Desenvolvimento e Validação ${ }^{1}$
}

\author{
Alice Moreira ${ }^{2}$ \\ Universidade Federal do Pará \\ Álvaro Tamayo \\ Universidade de Brasília
}

\begin{abstract}
RESUMO - A carência de instrumentos de mensuração confiáveis tem atrasado o desenvolvimento da pesquisa psicológica sobre dinheiro e fenômenos relacionados. O objetivo deste trabalho foi desenvolver e validar uma Escala de Significado do Dinheiro. Para desenvolver a escala, dados preliminares foram coletados com amostra heterogênea de 61 sujeitos e organizados através de procedimento incluindo análises de conteúdo, combinatória, semântica e de juízes. A compreensão teórica baseou-se em referencial das ciências sociais, resultando em um modelo hipotético com 10 fatores. A escala foi validada em amostra heterogênea com 1.464 sujeitos de todas as regiões brasileiras. Os resultados apontaram uma estrutura multifatorial ortogonal, confirmada separadamente para homens e mulheres, e constituída por 9 componentes: os alpha de Cronbach variaram entre 0,70 e 0,88 para 6 componentes; os demais foram 0,66, 0,67 e 0,57. Comparada aos estudos anteriores, esta escala apresenta avanços e abre novas possibilidades para pesquisas psicológicas em temas relacionados a dinheiro.
\end{abstract}

Palavras-chave: escalas de significado do dinheiro; psicologia do dinheiro; psicologia econômica.

\section{The Meaning of Money Scale: Development and Validation}

\begin{abstract}
The lack of reliable measurement tools has delayed the development of psychological research about money and related phenomena. The aim of this study was to develop and validate a Meaning of Money Scale. To develop the scale, preliminary data were collected using a heterogeneous sample of 61 subjects and organised through procedure including content, combinatory, semantic, by judges, and based on social sciences theoretical analysis. This resulted in a 10 factors hypothetical model. The scale was validated in a heterogeneous sample with 1464 subjects from all Brazilian regions. Results pointed to an orthogonal multifactorial structure, separately confirmed to men and women, and composed by 9 components: Cronbach alpha ranged from 0,70 to 0,88 to 6 components, and the others were $0,66,0,67$ and 0,57. Comparing to previous studies, this scale presents advances and generates new possibilities to psychological research about money related subjects.
\end{abstract}

Key words: meaning of money scales; psychology of money; economic psychology.

A carência de estudos sobre o dinheiro na literatura psicológica tem sido mencionada freqüentemente (Doyle, 1992; Furnham \& Argyle, 1998; Lewis, Webley \& Furnham, 1995) Entretanto, podemos encontrar formulações psicanalíticas sobre seus aspectos simbólicos inconscientes (Freud, 1908/ 1977; 1917/1977); estudos em Psicologia Organizacional sobre as propriedades motivacionais do pagamento (Baron \& Kenny, 1986; Cowherd \& Levine, 1992); e experimentos conduzidos em laboratórios examinando a forma da curva de utilidade marginal do dinheiro (Allison, 1983; Myerson \& Green, 1995). Nas últimas décadas, tem havido um au-

1 Trabalho desenvolvido como estudo preliminar para a preparação de tese de doutorado da primeira autora, em desenvolvimento no Instituto de Psicologia da Universidade de Brasília, sob orientação do segundo autor. Apoio financeiro da CAPES (Bolsa de Doutorado da primeira autora) e o CNPq (Bolsa de Pesquisa do segundo autor Processo Integrado n. 522277/95). Inscrito para apresentação na XXIX Reunião anual de Psicologia da Sociedade Brasileira de Psicologia

2 Endereço: Universidade de Brasília, Instituto de Psicologia, Departamento de Psicologia Social e do Trabalho. CEP: 70910-900 Brasília -DF. E-mail: alice@brnet.com.br; tamayo@unb.br mento do interesse de psicometristas e psicólogos sociais em produzir escalas para medir o significado ou as atitudes sobre o dinheiro (Furnham, 1984; Tang, 1992; Wernimont \& Fitzpatrick, 1972; Yamauchi \& Templer, 1982). Além de apresentarem alguns problemas psicométricos, estas escalas foram desenvolvidas apenas a partir de pressuposições teóricas limitadas ou de instrumentos anteriormente validados. Este trabalho relata a elaboração e a validação de um instrumento de medida para o significado do dinheiro no Brasil, baseado no levantamento de dados sobre a perspectiva do senso comum e na análise teórica destes dados a partir de um esquema referencial compreensivo das ciências sociais. O principal objetivo foi introduzir o estudo do significado do dinheiro no contexto brasileiro, a partir da disponibilização de um instrumento para subsidiar pesquisas sobre o comportamento econômico cotidiano, em áreas relacionadas a organizações e trabalho (Tang \& Gilbert, 1995; Thierry, 1992), consumo (Babin, Darden \& Griffin, 1994; Livingstone \& Lunt, 1993), problemas psicológicos (Hanley \& Wilhelm, 1992; Politano \& Lester, 1997), relações familiares (Kirchler, 1995; Pahl, 1995), ou problemas sociais de ordem mais ampla (Furnham, 1983; Kirchler, 1997; Lynn, 1993). 


\section{O dinheiro como objeto de estudo}

\section{O estudo do dinheiro nas Ciências Sociais}

Como o dinheiro participa de praticamente todas as áreas da vida social, ele se constitui em objeto para diversas disciplinas das ciências sociais, cada uma delas focalizando-o a partir de ângulos específicos (Doyle, 1992; Furnham \& Argyle, 1998). Os economistas buscam encontrar fórmulas matemáticas que permitam prever e controlar o comportamento econômico no nível agregado, pressupondo a universalidade e a neutralidade do dinheiro (Galbraith, 1987/1989). Os sociólogos voltam-se para os mecanismos institucionais e redes sociais que permitem ao dinheiro circular, interessando-se pela diversidade de usos e percepções sociais (Dodd, 1994/1997). Os antropólogos focalizam a origem, dogmas, rituais e costumes monetários em diferentes culturas, tentando detectar universalidade e especificidades culturais sobre o dinheiro (Dalton, 1971). Os cientistas políticos voltam-se para o seu significado nas políticas governamentais (Sorauf, 1992), e os teólogos abordam os aspectos éticos e morais de seu uso (Lamb, 1992). A falta de articulação entre as perspectivas constitui uma das dificuldades para a compreensão mais abrangente do assunto (Baker \& Jimerson, 1992).

A tentativa de articular as diversas perspectivas das ciências sociais foi esboçada recentemente por Baker e Jimerson. Eles propuseram um quadro compreensivo para os estudos sociológicos, antropológicos, psicológicos e econômicos sobre o dinheiro, considerando duas perspectivas opostas: a estrutural que, aproximando-se à visão dos economistas, encara o dinheiro dentro das estruturas sociais de modo racional, neutro e objetivo, e a cultural que enfatiza as interpretações simbólicas e não racionais, buscando significados evocativos. Ambas as perspectivas consideram as dimensões macro e micro. Assim sendo: (1) Macroestrutural focaliza o contexto regulatório legal e político, como mercado e comércio internacional; (2) Microestrutural concentra-se nas relações interpessoais de troca e comunicação; (3) Macrocultural focaliza os grandes sistemas de crença, valores e significados; e (4) Microcultural concentra-se nos valores, atitudes e crenças dos indivíduos e sua influência sobre o comportamento individual (Baker \& Jimerson, 1992).

\section{O estudo do dinheiro na Psicologia}

Os esforços de aproximação entre psicólogos e economistas, nos últimos anos, podem ser atestados pelo aumento de publicações, como livros textos (Allison, 1983; Furnham \& Argyle, 1998; Lea, Tarpy \& Webley, 1987; Lewis e cols., 1995) e revistas especializadas (The Journal of Economic Psychology; The Journal of Socioeconomics). Lewis e cols. (1995) sustentaram que algumas disciplinas de aparecimento recente refletem a multiplicidade de perspectivas teóricometodológicas em Psicologia, por exemplo, a Psicologia Experimental, a Economia Comportamental e a Psicologia Econômica, representando diferentes níveis de aproximação ou afastamento entre os princípios psicológicos e a racionalidade subjacente ao modelo econômico.
A Psicologia Econômica foi definida como a aplicação de princípios e métodos psicológicos aos eventos econômicos da vida cotidiana (Lewis \& cols., 1995). Entre os diversos tópicos abordados por esta disciplina, encontram-se temas tais como: posses materiais (Belk, 1991; Furby, 1991), o papel do dinheiro na dinâmica familiar (Burgoyne, 1995; Kirchler, 1993), manejo cotidiano do dinheiro incluindo débito e poupança (Groenland, Bloem \& Kuylen, 1996; Lea, Webley \& Walker, 1995), propriedades físicas do dinheiro (Furnham, 1985; Snelders, Hussein, Lea \& Webley, 1992), e a mensuração do significado ou atitudes para dinheiro (Furnham, 1984; Tang, 1992; Wernimont \& Fitzpatrick, 1972; Yamauchi \& Templer, 1982). Entretanto, não existe uma articulação teórica ou metodológica que organize os estudos empíricos encontrados em cada um destes tópicos (Lewis \& cols., 1995).

As atitudes com relação a dinheiro têm sido usadas como variáveis antecedentes para a função de utilidade marginal do dinheiro (Brandstaetter \& Brandstaetter, 1996), ou o desenvolvimento econômico de nações (Lynn, 1991; Yamauchi, Lynn \& Rendell, 1994). Alguns autores têm sugerido modelos teóricos onde o significado do dinheiro é colocado como uma das variáveis antecedentes para variáveis como bemestar subjetivo (Porter \& Garman, 1992), para o significado do pagamento ou satisfação no trabalho (Thierry, 1992). É possível, ainda, imaginar que o significado do dinheiro possa ter influência sobre outros fenômenos tais como: dinâmica familiar, socialização econômica das crianças, manejo cotidiano do dinheiro, importância das posses materiais, consumo compulsivo, pagamento de impostos ou doações para caridade. A carência de instrumentos de mensuração confiáveis tem sido apontada como uma dificuldade para a extensão dos estudos relacionados aos aspectos psicológicos do dinheiro (Furnham \& Argyle, 1998).

Medina e colaboradores apresentaram um quadro sistematizando as características metodológicas de onze estudos empíricos, onde cinco diferentes instrumentos e modificações deles foram utilizados (Medina, Saegert \& Gresham, 1996). As características dos quatro instrumentos que têm sido mais utilizados em pesquisas estão sumariadas abaixo: I. "The Modified Semantic Differential" ou Diferencial Semântico Modificado

Postulando que o significado do dinheiro é uma função de diferentes histórias de aprendizagem, Wernimont e Fitzpatrick (1972) trabalharam com uma amostra de 533 sujeitos com experiências de vida diferenciadas, incluindo freiras, desempregados, cientistas, engenheiros e vendedores, entre outros. $\mathrm{O}$ instrumento foi construído na forma de diferencial semântico com 40 pares de adjetivos, e os resultados indicaram cinco componentes explicando 48,28\% da variância: Fracasso e Vergonha, Aceitabilidade Social, Atitude "oraora" (ou de desimportância), Pecado Moral, e Segurança Confortável.

\section{II. "The Money Attitude Scale" ou Escala de Atitudes para Dinheiro}

Yamauchi e Templer (1982) basearam-se na literatura clínica psicanalítica para elaborar um questionário de 62 itens, com escalas Likert de 7 pontos, que foram administra- 
dos a 300 sujeitos de ambos os sexos, com renda anual e ocupações variadas. Os resultados apontaram cinco componentes, com 34 itens explicando 33,6\% da variância: Poderprestígio; Retenção; Desconfiança; Qualidade nas compras, e Ansiedade. $\mathrm{O}$ quarto componente foi eliminado por motivos teóricos e a versão final do instrumento ficou constituída por quatro componentes.

III. "Money Beliefs and Behaviour Scale" ou Escala de Crenças e Comportamentos Monetários

Furnham (1984) desenvolveu seu instrumento usando 60 itens, com escalas de 7 pontos, combinando itens retirados de três fontes: a Escala de Atitudes para Dinheiro (Yamauchi \& Templer, 1982); a taxonomia sugerida por Goldberg e Lewis (1978) e pesquisa realizada por Rubinstein, nos Estados Unidos (Rubinstein, 1981). A amostra contou com 256 sujeitos, entre 18 e 30 anos de idade, com renda anual e ocupações variadas. Os resultados apontaram seis fatores ou componentes com 35\% de variância explicada: Obsessão; Poder/gastar; Retenção; Segurança-conservativa; Inadequação e Esforço-habilidade.

IV. “The Money Ethic Scale” ou Escala Ética do Dinheiro

A escala foi construída e validada por Tang (1992), com base na hierarquia de necessidades de Maslow (1954) e nas três escalas citadas acima. Cinqüenta itens, com escalas Likert de 7 pontos, foram administrados a 249 trabalhadores em tempo integral e a análise confirmou a existência dos seis componentes que haviam sido hipotetizados, com 30 itens explicando 42,8\% da variância: Bom; Mal; Realização; Respeito; Orçamento e Poder-liberdade.

Estes instrumentos apresentam alguns problemas, como terem sido desenvolvidos a partir de pressuposições teóricas não claramente formuladas (Wernimont \& Fitzpatrick, 1972; Yamauchi \& Templer, 1982), ou dos trabalhos anteriores (Furnham, 1984; Tang, 1992), reproduzindo as mesmas limitações, ou seja: ausência de um levantamento empírico inicial, ignorando a perspectiva leiga, e uso de bases teóricas restritas, desconsiderando o caráter multidisciplinar do dinheiro. Além disso, eles foram validados com amostras pequenas e enviesadas. A maioria dos autores relatou ter utilizado a técnica dos Componentes Principais com rotação Varimax, sem justificar o uso, deixando dúvidas se os componentes encontrados eram realmente ortogonais. Furnham (1984) referiu-se ao uso de Análise Fatorial sem mencionar que técnicas foram empregadas. $\mathrm{O}$ critério de carga fatorial maior que 0,40 foi estabelecido, mas relaxado para alguns dos componentes em todos os trabalhos, com exceção de Tang. As descrições de resultados são incompletas, ou pouco claras, quanto a aspectos psicométricos relevantes, como testes de confiabilidade ou percentuais de variância explicada por cada componente, também com exceção de Tang. Os índices alpha de Cronbach, quando relatados, variaram entre 0,68 a 0,81 (Tang; Yamauchi \& Templer).

Furnham e Argyle (1998) enfatizaram que estas quatro escalas chegaram a resultados semelhantes quanto ao número de componentes encontrados. Outras semelhanças também podem ser mencionadas, quanto aos conteúdos dos componentes e à formulação dos itens, principalmente entre as três ultimas escalas, mas isto pode ser visto antes como um reflexo do fato de elas terem sido baseadas umas nas outras, do que como um indicativo de confiabilidade dos resultados. Apesar das semelhanças, estudos conduzidos com estes instrumentos têm apontado um quadro contraditório com respeito às variáveis correlacionadas. Revisando resultados obtidos em uma série de estudos, onde diferentes instrumentos foram utilizados, Furnham e Argyle concluíram que alguns fatores aparecem como claramente relacionados a traços clínicos, como obsessão e ansiedade, enquanto outros parecem mais ligados a crenças e a variáveis demográficas, como idade, sexo, classe social e nacionalidade. Para os autores, embora pareça haver padrões consistentes, ainda não foi possível chegar a conclusões seguras pela falta de estudos comparáveis em larga-escala populacional.

\section{Método}

Neste estudo, optamos por um procedimento que privilegiou os dados empíricos, sem considerar o referencial da literatura na primeira fase do trabalho. O processo de elaboração do instrumento descreve como os dados preliminares foram coletados, organizados e analisados, de modo a gerar fatores hipotéticos e itens para o questionário. No tópico seguinte, é descrita a validação do instrumento.

\section{O processo de elaboração do instrumento}

\section{Elaboração de um esquema fatorial hipotético}

\section{Amostra}

Foram utilizados 61 sujeitos, divididos em 12 grupos com 5 sujeitos em cada, com exceção do Grupo 4, que contou com 6 sujeitos. As variáveis sexo, faixa etária e nível de renda familiar foram controladas conforme a Tabela 1 .

Os Grupos 1 e 2 foram contatados em escolas públicas e os Grupos 3 e 4 em uma mesma escola da rede privada. Os Grupos 5 e 6 foram constituídos por funcionários de uma universidade pública que ocupavam cargos de servente, auxiliar e jardineiro. Os Grupos 7 e 8 foram constituídos por funcionários de um banco estatal, em cargos de gerência e

Tabela 1 - Descrição dos grupos da amostra para coleta de dados

\begin{tabular}{rrlcrr}
\hline Grupo & N & \multicolumn{1}{c}{ Sexo } & $\begin{array}{c}\text { Média } \\
\text { de idade }\end{array}$ & \multicolumn{2}{c}{$\begin{array}{c}\text { Renda } \\
\text { familiar média }\end{array}$} \\
\hline 1 & 5 & Homens & 19,6 & $\mathrm{R} \$$ & 860,00 \\
2 & 5 & Mulheres & 18,0 & $\mathrm{R} \$$ & 458,00 \\
3 & 5 & Homens & 17,2 & $\mathrm{R} \$$ & $4.300,00$ \\
4 & 6 & Mulheres & 19,0 & $\mathrm{R} \$$ & $3.858,34$ \\
5 & 5 & Homens & 31,4 & $\mathrm{R} \$$ & 458,00 \\
6 & 5 & Mulheres & 36,0 & $\mathrm{R} \$$ & 601,25 \\
7 & 5 & Homens & 31,0 & $\mathrm{R} \$$ & $4.200,00$ \\
8 & 5 & Mulheres & 39,0 & $\mathrm{R} \$$ & $4.414,00$ \\
9 & 5 & Homens & 69,2 & $\mathrm{R} \$$ & 371,20 \\
10 & 5 & Mulheres & 68,6 & $\mathrm{R} \$$ & $1.380,00$ \\
11 & 5 & Homens & 64,4 & $\mathrm{R} \$$ & $7.740,00$ \\
12 & 5 & Mulheres & 57,4 & $\mathrm{R} \$$ & $5.608,40$ \\
Geral & 61 & & 39,6 & $\mathrm{R} \$$ & $2.911,07$ \\
\hline
\end{tabular}


assessoria. Os Grupos 10 e 12 foram contatados em clubes de terceira idade. No Grupo 9, quatro sujeitos foram contatados em um abrigo para idosos, e o quinto em um clube de terceira idade. Os sujeitos do Grupo 11 eram funcionários públicos aposentados e tiveram que ser contatados individualmente em suas residências. Todos os sujeitos dos Grupos 1 a 4 eram solteiros, e nos Grupos 5 a 12 predominaram os casados (23 sujeitos). Predominou a religião católica (38 sujeitos) e a maioria dos sujeitos respondeu não ter preferência por partido político (48 sujeitos).

\section{Procedimento}

Os sujeitos escreveram individualmente, durante dez minutos, uma lista de palavras relacionadas ao significado do dinheiro para si. A lista foi recolhida, seguindo-se uma discussão em grupo de aproximadamente 40 minutos, exceto para um sujeito do Grupo 9 e todos os do Grupo 11, entrevistados individualmente. Foi usado um esquema semiestruturado com três tópicos: (1) o significado do dinheiro para cada participante; (2) os fatores que eles acreditavam ter influência sobre o significado do dinheiro para as pessoas em geral; e (3) o que eles acreditavam que deveria ser levado em conta em uma pesquisa sobre o significado do dinheiro. Os sujeitos foram incentivados a acrescentar palavras às suas listas após a discussão. Ao final, preencheram um questionário com dados pessoais e demográficos.

\section{Análise dos dados}

Os sujeitos produziram 494 palavras diferentes, cujas frequiências variaram de 1 a 19. Na apuração de freqüências, foram mantidas as exatas palavras escritas, considerando-se como palavras diferentes as variações de uma mesma palavra em número (por exemplo: carro e carros), classe gramatical (por exemplo: compra e comprar) ou por meio de complementos (por exemplo: alimentação e boa alimentação). As discussões grupais foram gravadas e transcritas literalmente.

Para organizar os dados, foram utilizados três grupos de juízes, formados por três estudantes de psicologia; cada grupo em diferente estágio de formação: recém-ingressos, meio do curso, e final do curso ou pós-graduação. As palavras produzidas pelos sujeitos foram submetidas à análise de conteúdo, feita pelos grupos separadamente. Cada grupo foi informado do procedimento usado na coleta e recebeu uma cópia da lista com as exatas palavras ordenadas pela frequiência. Os juízes discutiram o(s) significado(s) atribuído(s) a cada palavra, e as agruparam formando categorias de significados, agrupando também variações gramaticais como uma mesma palavra, quando acharam conveniente. Cada categoria foi definida e denominada por concordância grupal.

Foram produzidos três conjuntos com 8 a 10 categorias, bastante semelhantes entre si. Eles foram combinados por meio de um procedimento comparativo, conduzido pela pesquisadora e duas auxiliares de pesquisa, usando como critérios as superposições entre as categorias, as definições da- das às categorias, as palavras incluídas e os significados atribuídos às palavras. O procedimento resultou em um quadro de categorias de palavras, consistindo em 11 categorias e 67 subcategorias.

As transcrições das discussões grupais foram utilizadas para gerar itens. Em cada transcrição, todas as frases que expressavam idéias sobre o significado do dinheiro foram selecionadas pela pesquisadora e auxiliares, sendo replicadas literalmente ou, quando necessário, foram feitas transformações gramaticais para adequá-las aos critérios sistematizados por Pasquali (1996; 1999). Por exemplo, advérbios foram retirados, como na frase: "Dinheiro lembra demais dívidas" para "Dinheiro lembra dívidas". Formas negativas foram transformadas em positivas, como "Eu não sou apegado a coisas materiais" para "Eu sou desapegado de coisas materiais". O quadro de categorias de palavras produzido anteriormente foi utilizado como referência para organizar os 1.764 itens gerados, por meio das mesmas 11 categorias e 67 subcategorias. Os dois apresentaram grande similaridade entre si. Todas as categorias e subcategorias que resultaram do trabalho com as listas de palavras foram preenchidas com itens retirados das entrevistas, com variações entre os percentuais, como pode ser visto na Tabela 2.

Tomando como referência as quantidades de palavras e de itens, e as qualidades psicométricas e relevância aparente dos itens, foi feita uma seleção de 10 categorias a serem usadas como fatores hipotéticos para o questionário. Cada fator hipotético foi composto por 20 itens, totalizando 200 itens. Tendo em vista a inevitável soma de decisão pessoal envolvida nesta seleção, nenhum teste de confiabilidade foi

Tabela 2 - Comparação de percentuais entre os quadros de categorias de palavras e itens

\begin{tabular}{|c|c|c|c|}
\hline C ategorias & $\begin{array}{c}\% \\
\text { palavras }\end{array}$ & $\begin{array}{l}\% \\
\text { itens }\end{array}$ & Exemplos de Subcategorias \\
\hline Poder & 13,4 & 17,5 & $\begin{array}{l}\text { Poder, status, vaidade, admiração, } \\
\text { dominação, conquista, fama, } \\
\text { gastar }\end{array}$ \\
\hline $\begin{array}{l}\text { Conseqüências } \\
\text { negativas } \\
\text { subjetivas }\end{array}$ & 12,3 & 22,6 & $\begin{array}{l}\text { Falsidade, ambição, tristeza, } \\
\text { arrogância, preocupação, ilusões, } \\
\text { solidão, decepções, loucura, } \\
\text { desconfiança, pecado, raiva }\end{array}$ \\
\hline $\begin{array}{l}N \text { ecessidades } \\
\text { básicas }\end{array}$ & 12,0 & 7,4 & $\begin{array}{l}\text { Saúde, sobrevivência, alimento, } \\
\text { vestuário, escolaridade }\end{array}$ \\
\hline Estabilidade & 10,9 & 9,7 & $\begin{array}{l}\text { Segurança, moradia, conforto, } \\
\text { família, futuro, estabilidade, } \\
\text { poupança }\end{array}$ \\
\hline $\begin{array}{l}\text { Conseqüências } \\
\text { negativas sociais }\end{array}$ & 9,3 & 13,5 & $\begin{array}{l}\text { Dívidas, pobreza, brigas e } \\
\text { inimizades, morte, desigualdade } \\
\text { social, roubo, corrupção }\end{array}$ \\
\hline Prazer & 9,2 & 3,8 & L azer, prazer, viagens \\
\hline Posses materiais & 8,8 & 4,2 & B ens materiais, riqueza, luxo \\
\hline $\begin{array}{l}\text { Conseqüências } \\
\text { positivas } \\
\text { subjetivas }\end{array}$ & 8,1 & 7,9 & $\begin{array}{l}\text { Felicidade, tranqüilidade, } \\
\text { liberdade, amor, virtude, auto- } \\
\text { confiança, consciência, sonho }\end{array}$ \\
\hline Transcendência & 6,6 & 6,5 & $\begin{array}{l}\text { Caridade, espiritualidade, } \\
\text { solidariedade, desapego }\end{array}$ \\
\hline $\begin{array}{l}\text { Conseqüências } \\
\text { positivas sociais }\end{array}$ & 5,0 & 3,6 & $\begin{array}{l}\text { Educação/cultura, progresso, } \\
\text { facilidades }\end{array}$ \\
\hline O rigem/fonte & 4,4 & 3,3 & Trabalho, esforço \\
\hline
\end{tabular}




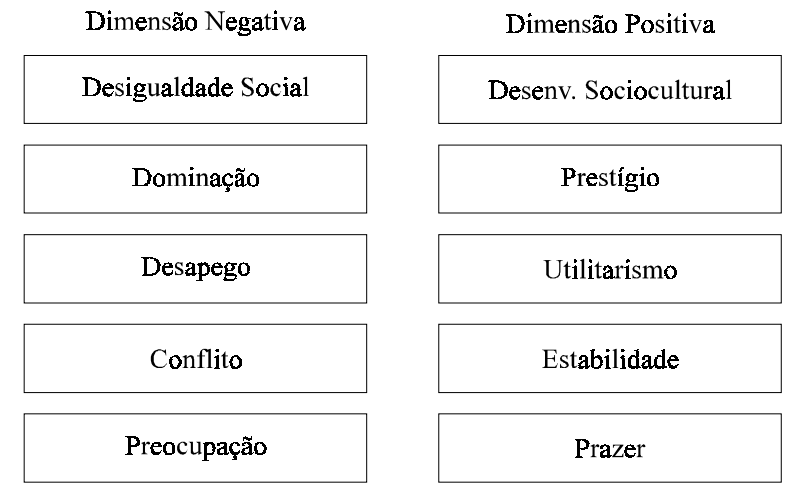

Figura 1 - Esquema fatorial hipotético organizado em níveis e dimensões

tentado nesse momento. Os fatores hipotéticos foram então comparados ao referencial da literatura, e esta comparação permitiu compreendê-los como duas dimensões opostas, positiva e negativa, organizadas em cinco níveis que atravessam desde o macrosocial até o microindividual (ver Figura 1), conforme a sugestão de Baker e Jimerson (1992).

No primeiro nível, foi colocada uma oposição entre $D e$ sigualdade Social e Desenvolvimento Socio-Cultural, que se refere a aspectos de ordem macroestrutural, ou seja, o que os indivíduos atribuem ao dinheiro em relação ao contexto social mais amplo. No segundo nível, foi hipotetizada uma oposição entre Dominação e Prestígio, enfatizando aspectos predominantemente simbólicos, positivos e negativos, atribuídos ao dinheiro no contexto social mais amplo. No terceiro nível, encontramos uma oposição entre Desapego e Utilitarismo, que se pretende como um nível intermediário entre macro e micro, pois refere-se a significados individuais de ordem filosófica ou ideológica, e sua influência sobre o comportamento individual pode ter repercussões na ordem social mais ampla. No quarto nível, foi colocada uma oposição entre Conflito e Estabilidade, referindo-se às consequiências atribuídas ao dinheiro no contexto das relações interpessoais, que correspondem à dimensão micro. No quinto nível, foi colocada uma oposição entre Preocupação e Prazer, que remete mais diretamente ao nível da subjetividade individual.

\section{Análise semântica e de juízes}

Anteriormente à validação estatística, foram conduzidas duas etapas preparatórias: análise semântica e análise de juízes. Para a análise semântica, uma lista randomicamente ordenada com os 200 itens foi apresentada a um grupo com 5 estudantes de ambos os sexos, cursando as primeiras séries do segundo grau. Cada item foi lido em voz alta e os sujeitos solicitados a enunciar, com suas próprias palavras, o que haviam entendido. Itens que evocaram qualquer dúvida, ou compreensão diferente do significado pretendido, ou ainda discordâncias entre os sujeitos foram assinalados e imediatamente explorados. Oito itens foram assinalados. Dois deles foram eliminados e os outros seis receberam novas elaborações. A lista modificada foi então apresentada a um segundo grupo com as mesmas características e o procedimento repetido. Desta vez, nenhum item foi marcado, não sendo necessário constituir um terceiro grupo.

A análise de juízes representou um teste de confiabilidade para o esquema hipotético, de modo a assegurar que os itens que compunham cada fator transmitiam o conteúdo semântico pretendido e permitiam discriminar os fatores. Foram utilizados como juízes 5 estudantes de Psicologia já familiarizados com a pesquisa, uma vez que haviam participado no processo de categorização das palavras. A cada juiz, separadamente, foi entregue um conjunto de três materiais: (1) a lista randomicamente ordenada com os 198 itens; (2) uma tabela em branco com colunas numeradas de 1 a 10 , correspondendo aos fatores hipotéticos, e linhas numeradas de 1 a 198, correspondendo aos itens; (3) um esquema contendo os nomes e definições de cada fator. Cada juiz foi solicitado a assinalar na tabela em branco a qual fator cada item deveria pertencer. Os itens poderiam ser assinalados em mais de um fator. A apuração dos resultados respeitou o critério de $80 \%$ de concordância entre os juízes e itens marcados em mais de dois fatores por pelo menos um juiz foram também eliminados. Como resultado, foram eliminados 40 itens, reduzindo-se o questionário para 158 itens, com a seguinte distribuição destes por fator hipotético: $\mathrm{FH} 1:$ 17, FH2: 14, FH3: 15, FH4: 16, FH5: 15, FH6: 16, FH7: 18, FH8: 16, FH9: 16, FH10: 15.

\section{Validação do instrumento}

\section{Amostra}

A constituição da amostra objetivou garantir o máximo de abrangência geográfica no país e heterogeneidade de características demográficas. O único critério estipulado foi o nível de escolaridade a partir do segundo grau incompleto. Três mil questionários foram distribuídos por meio de uma rede de colaboradores que procedeu a aplicação nas diferentes regiões do país, com quantidades aproximadas enviadas para cada região. Foram recebidos de volta 1.458 questionários aproveitáveis, considerando-se um máximo de $10 \%$ de respostas faltosas para utilização de cada questionário. A amostra final por região ficou constituída como segue: Região Norte $(315=21,2 \%)$, Região Nordeste $(207=13,9 \%)$, Região Centroeste $(475=32 \%)$, Região Sudeste $(316=$ $21,3 \%)$, Região Sul $(155=10,4 \%)$ e $17(1,1 \%)$ não declararam o lugar de residência. Quanto ao sexo, $876(59 \%)$ eram mulheres, $595(40,1 \%)$ homens e $14(0,9 \%)$ não declararam. A idade variou de 14 a 74 anos, com média de 30,6 e desvio padrão de 11,7. A renda familiar mensal média foi de $\mathrm{R} \$ 3.003,59$, com desvio padrão de $\mathrm{R} \$ 2.858,25$. A renda familiar mensal mínima foi de $\mathrm{R} \$ 120,00$ e a máxima de $\mathrm{R} \$ 27.000,00$. O nível de escolaridade distribuiu-se como segue: segundo grau incompleto $=291(19,6 \%)$; segundo grau completo $=389(26,2 \%)$; terceiro grau incompleto $=$ $311(20,9 \%)$; terceiro grau completo $=457(30,8 \%)$; pósgraduação $=4(0,3 \%)$ e não declararam $=33(2,2 \%)$. Os respondentes declararam 216 diferentes ocupações, representando um largo espectro de ramos de atividades, desde estudantes, donas de casa, aposentados, profissionais de ní- 
veis diferentes envolvidos com saúde, educação, comunicação, justiça, informática, estética, esportes, artes, segurança, construção, burocracia, finanças e outros.

\section{Procedimento}

Os questionários foram enviados aos colaboradores em cada ponto do país pelo correio. A tarefa dos colaboradores foi distribuir os questionários e recebê-los de volta após preenchidos. A situação em que os respondentes foram contatados (escolas, locais de trabalho ou residências) e o prazo para devolução variou em cada lugar, dependendo da disponibilidade dos colaboradores. Os questionários foram mandados de volta para a pesquisadora por correio.

\section{Análises dos dados}

As análises dos dados foram feitas por meio do SPSS. Primeiramente, foi feita a verificação da precisão dos dados, presença de dados faltosos e adequação aos pressupostos para análise multivariada (Tabachnick \& Fidell, 1996). A análise descritiva preliminar revelou que nenhum item excedia o critério de $5 \%$ de dados faltosos, mas indicou a existência de 6 itens não-discriminativos, ou seja, mais de 70\% dos respondestes assinalaram 5 na escala (skewness $>-2,5$ ), que foram eliminados (exemplos: "Dinheiro pode ser ganho honestamente"; "Famílias precisam ter segurança financeira"). Por meio da Análise de Regressão, usando a variável número do sujeito na amostra como dependente e os 158 itens como preditores, foram detectados e eliminados 21 outliers (casos atípicos) multivariados, usando o critério de distância Mahalanobis com $p<0,001\left(\chi^{2}=149,449\right)$. A linearidade verificada por meio do scatterplot, foi considerada satisfatória.

A extração dos Componentes Principais com rotação Varimax foi iniciada com 152 itens e os 1.464 sujeitos que permaneceram na amostra. A fatorabilidade foi considerada satisfatória $(K M O=0,918)$. Foi estabelecido o critério de carga fatorial maior que 0,40 para inclusão dos itens. Com o critério de eingenvalue maior que 1 , foram apontados 39 componentes, explicando 55,83\% de variância. Por meio do screen plot, foi percebido que 9 componentes explicavam $30,68 \%$ de variância. Foi então realizada mais uma extração, por meio da mesma técnica, solicitando-se 9 componentes. A partir das matrizes rotadas destas duas soluções, foram eliminados os itens que não alcançaram o critério de carga fatorial em nenhuma das duas soluções. Os 120 itens restantes foram submetidos novamente à mesma técnica de análise, solicitando-se a extração de nove componentes. A solução final ficou constituída por 82 itens que, em conjunto, explicaram $33,62 \%$ da variância dos dados.

A possibilidade de estruturas fatoriais diferentes para homens e mulheres foi verificada, repetindo-se o mesmo procedimento de extração separadamente. A consistência da estrutura fatorial foi confirmada, uma vez que exatamente os mesmos componentes foram encontrados, alterando-se apenas sua ordem e o número de itens em cada componente. A adequação das técnicas de extração e rotação foi também verificada, por meio de Análise Fatorial dos Eixos Principais solicitando 9 fatores. Novamente foram encontrados os mesmos agrupamentos de itens e a matriz de correlação dos fatores indicou apenas quatro correlações maiores que 0,30 , mas todas menores que 0,33 , o que foi considerado como confirmação da adequação da análise dos Componentes Principais com rotação Varimax.

\section{Resultados}

A solução fatorial, incluindo itens com cargas fatoriais e comunalidades, mais o número de itens, o percentual de variância explicada e o alpha de Cronbach para cada componente encontram-se na Tabela 3 (o instrumento completo está em anexo). Na tabela, foram incluídas apenas as cargas fatoriais superiores a 0,40 . Praticamente todos os 82 itens obtiveram cargas expressivas em apenas um componente, apresentando cargas fatoriais muito baixas nos demais. Apenas 6 entre os 82 itens obtiveram carga fatorial maior que 0,30 em um segundo componente, sendo que dois destes tiveram carga superior a 0,40 , como pode ser visto na Tabela 3.

O primeiro componente foi denominado como "Prazer". Seus itens refletiram conseqüências positivas atribuídas ao dinheiro, tais como: prazer, felicidade, bem-estar psicológico, auto-estima, esperança e harmonia nas relações interpessoais. O segundo componente foi denominado como "Poder", por transmitir a crença de que o dinheiro é fonte de autoridade, prestígio e reconhecimento social, assegurando uma situação privilegiada a quem o possui. $\mathrm{O}$ terceiro componente foi denominado como "Conflito". Ele indicou um significado negativo atribuído ao dinheiro no contexto das relações interpessoais cotidianas, com a crença de que o dinheiro provoca desconfiança, conflitos, desavenças, mortes, falsidade, neurose e oportunismo entre as pessoas. A idéia transmitida pelo quarto componente foi "Desapego", indicando crenças e comportamentos que envolvem uma oposição entre dinheiro e espiritualidade, e a necessidade de dar mais importância aos valores de solidariedade e generosidade que aos bens materiais. O quinto componente, "Sofrimento", indicou um significado negativo atribuído ao dinheiro no nível da subjetividade, envolvendo fortes emoções carregadas por sofrimento e aspectos de desequilíbrio emocional. O sexto componente foi denominado como "Progresso", por transmitir um significado positivo atribuído ao dinheiro em relação ao contexto social mais amplo, como promotor de progresso para as sociedades e a humanidade como um todo, capaz de resolver problemas sociais e construir um mundo melhor. O sentido do sétimo componente foi o de "Desigualdade", ou seja, o dinheiro é visto como fonte de desigualdade social, segregação e preconceito, criando uma forte demarcação no espaço social. O oitavo componente foi denominado como "Cultura". Seus itens refletem um significado positivo atribuído ao dinheiro, como promotor do desenvolvimento cultural, transmitindo a disposição pessoal de investir no desenvolvimento das ciências, artes, cultura e tecnologia. O nono componente foi denominado como 
Tabela 3 - Solução fatorial com as cargas fatoriais e comunalidades por item(*) nas colunas, e número de itens, percentual de variância explicada e alphas de Cronbach por componente nas linhas inferiores

\begin{tabular}{|c|c|c|c|c|c|c|c|c|c|c|}
\hline Itens(**)/C omponentes(***) & C 1 & C 2 & C 3 & C 4 & C 5 & C 6 & C 7 & C 8 & C 9 & $\mathbf{h}^{2}$ \\
\hline Dinheiro ajuda a ser feliz & 0,659 & & & & & & & & & 0,483 \\
\hline Significa prazer & 0,647 & & & & & & & & & 0,476 \\
\hline A trai felicidade & 0,626 & & & & & & & & & 0,473 \\
\hline Harmonia familiar & 0,580 & & & & & & & & & 0,447 \\
\hline Relações amorosas & 0,566 & & & & & & & & & 0,393 \\
\hline Busca de felicidade & 0,563 & & & & & & & & & 0,417 \\
\hline Gostar mais de si & 0,513 & & & & & & & & & 0,350 \\
\hline Facilita vida sexual & 0,466 & & & & & & & & & 0,304 \\
\hline Facilita convivência familiar & 0,457 & & & & & & & & & 0,377 \\
\hline Uso para ficar contente & 0,449 & & & & & & & & & 0,286 \\
\hline Possibilita ascensão social & 0,422 & & & & & & & & & 0,416 \\
\hline Esperança no futuro & 0,414 & & & & & & & & & 0,322 \\
\hline Poder viajar & 0,412 & & & & & & & & & 0,330 \\
\hline Quando compro esqueço & 0,405 & & & & & & & & & 0,278 \\
\hline A utoridade sobre outros & & 0,585 & & & & & & & & 0,424 \\
\hline Rico impõe personalidade & & 0,575 & & & & & & & & 0,418 \\
\hline Centro das atenções & & 0,565 & & & & & & & & 0,486 \\
\hline Primeiro a ser atendido & & 0,545 & & & & & & & & 0,366 \\
\hline Pessoas submetem-se & & 0,541 & & & & & & & & 0,414 \\
\hline Passa por cima das normas & & 0,527 & & & & & & & & 0,377 \\
\hline Ter prestígio & & 0,521 & & & & & & & & 0,387 \\
\hline Se livra de entrar em filas & & 0,521 & & & & & & & & 0,358 \\
\hline Educadas para mandar & & 0,490 & & & & & & & & 0,318 \\
\hline Classe pobre excluída & & 0,482 & & & & & & & & 0,282 \\
\hline Rico pode impor opinião & & 0,458 & & & & & & & & 0,310 \\
\hline Pessoas tentam agradar & & 0,429 & & & & & & & & 0,376 \\
\hline Reconhecimento social & & 0,423 & & & & & & & & 0,370 \\
\hline Ter poder & & 0,419 & & & & & & & & 0,373 \\
\hline Cometer crimes impunemente & & 0,416 & & & & & & & & 0,277 \\
\hline Sinônimo de dominação & & 0,414 & & & & & & & & 0,371 \\
\hline Status social & & 0,413 & & & & & & & & 0,377 \\
\hline Desconfiança entre pessoas & & & 0,637 & & & & & & & 0,461 \\
\hline Provoca traições & & & 0,634 & & & & & & & 0,445 \\
\hline Causa assassinatos & & & 0,592 & & & & & & & 0,404 \\
\hline Provoca neuroses & & & 0,572 & & & & & & & 0,382 \\
\hline Desavença com parentes & & & 0,565 & & & & & & & 0,375 \\
\hline Descontrole emocional & & & 0,551 & & & & & & & 0,409 \\
\hline Torna pessoas oportunistas & & & 0,549 & & & & & & & 0,432 \\
\hline Atrai inveja & & & 0,534 & & & & & & & 0,430 \\
\hline Gera ingratidão & & & 0,525 & & & & & & & 0,407 \\
\hline A trai falsos amigos & & & 0,519 & & & & & & & 0,407 \\
\hline Provoca ilusões & & & 0,518 & & & & & & & 0,300 \\
\hline Lembra dívidas & & & 0,462 & & & & & & & 0,321 \\
\hline Gera desarmonia nas famílias & & & 0,450 & & & & & & & 0,316 \\
\hline Casamentos por interesse & & & 0,446 & & & & & & & 0,332 \\
\hline Sinônimo de dor de cabeça & & & 0,421 & & & & & & & 0,388 \\
\hline Quem tem fé & & & & 0,572 & & & & & & 0,385 \\
\hline Recompensas espirituais & & & & 0,561 & & & & & & 0,353 \\
\hline Ajudar quem precisa & & & & 0,540 & & & & & & 0,382 \\
\hline Dar menos importância & & & & 0,521 & & & & & & 0,359 \\
\hline Ensinar filhos generosos & & & & 0,521 & & & & & & 0,398 \\
\hline É dever dividir & & & & 0,487 & & & & & & 0,387 \\
\hline Ajudar amigos & & & & 0,455 & & & & & & 0,254 \\
\hline Sou desapegado & & & & 0,451 & & & & & & 0,353 \\
\hline Basta crer em Deus & & & & 0,443 & & & & & & 0,433 \\
\hline
\end{tabular}


Continuação da Tabela 3

\begin{tabular}{|c|c|c|c|c|c|c|c|c|c|c|}
\hline Itens(**)/Componentes(***) & C 1 & C 2 & C 3 & C 4 & C 5 & C 6 & C 7 & C 8 & C 9 & $\mathbf{h}^{2}$ \\
\hline Provoca angústia & & & 0,431 & & 0,533 & & & & & 0,506 \\
\hline Provoca frustrações & & & 0,443 & & 0,497 & & & & & 0,476 \\
\hline Coisa complicada & & & & & 0,491 & & & & & 0,298 \\
\hline Tenho pesadelos & & & & & 0,483 & & & & & 0,327 \\
\hline M e deixa deprimido & & & & & 0,469 & & & & & 0,302 \\
\hline Constrói um mundo melhor & & & & & & 0,620 & & & & 0,516 \\
\hline Evolução da humanidade & & & & & & 0,559 & & & & 0,415 \\
\hline Facilita a vida da humanidade & & & & & & 0,526 & & & & 0,459 \\
\hline Gera progresso & & & & & & 0,475 & & & & 0,443 \\
\hline Resolve problemas sociais & & & & & & 0,447 & & & & 0,359 \\
\hline Garante prosperidade & & & & & & 0,438 & & & & 0,404 \\
\hline Valorizado socialmente & & & & & & & 0,448 & & & 0,349 \\
\hline Pobres impedidos de ir & & & & & & & 0,445 & & & 0,286 \\
\hline Negros e pobres perigosos & & & & & & & 0,426 & & & 0,279 \\
\hline Lembra contrastes sociais & & & & & & & 0,422 & & & 0,329 \\
\hline Evitar contato com crianças & & & & & & & 0,410 & & & 0,361 \\
\hline Provoca jogos de interesse & & & & & & & 0,409 & & & 0,297 \\
\hline Pesquisas científicas & & & & & & & & 0,746 & & 0,584 \\
\hline Eventos culturais & & & & & & & & 0,710 & & 0,539 \\
\hline Desenvolvimento das artes & & & & & & & & 0,704 & & 0,535 \\
\hline Inovações tecnológicas & & & & & & & & 0,646 & & 0,480 \\
\hline Desenvolvimento do país & & & & & & & & 0,456 & & 0,306 \\
\hline Completamente realizado & & & & & & & & & 0,544 & 0,344 \\
\hline Família amparada & & & & & & & & & 0,505 & 0,326 \\
\hline Convênios de saúde & & & & & & & & & 0,462 & 0,296 \\
\hline Seguro de vida & & & & & & & & & 0,445 & 0,294 \\
\hline M edo de gastar & & & & & & & & & 0,404 & 0,248 \\
\hline Número de itens & 14 & 17 & 15 & 9 & 5 & 6 & 6 & 5 & 5 & \\
\hline \%Variância explicada total = 33,62\% & 5,93 & 5,88 & 5,65 & 2,89 & 2,88 & 2,77 & 2,71 & 2,56 & 2,35 & \\
\hline Alpha de Cronbach & 0,84 & 0,88 & 0,87 & 0,73 & 0,67 & 0,80 & 0,66 & 0,76 & 0,57 & \\
\hline
\end{tabular}

(*) São apresentadas apenas cargas fatoriais acima de 0,40

(**) Itens abreviados transmitindo apenas a idéia principal

(***) $\quad \mathrm{C} 1=$ Prazer; $\mathrm{C} 2=$ Poder; C3 = Conflito; C4 = Desapego; C5 = Sofrimento; C6 = Progresso; C7 = Desigualdade; C8 = Cultura; C9 = Estabilidade

"Estabilidade", por transmitir a crença de que o dinheiro é fonte de estabilidade e segurança, referindo-se a crenças e comportamentos relacionados à importância de ter as necessidades básicas asseguradas e estabilidade financeira.

\section{Discussão}

A estratégia de trabalho para desenvolver a Escala de Significado do Dinheiro (ESD) foi tomar o senso comum como ponto de partida, utilizando o referencial teórico das ciências sociais para sua compreensão. O primeiro passo foi detectar um conjunto de associações simbólicas produzidas por pessoas representativas da população em geral. Para compreender a estrutura subjacente a estas associações foram utilizados juízes em processo de formação acadêmica, que não estavam diretamente familiarizados com a literatura sobre temas relacionados à Psicologia Econômica, embora detivessem diferentes graus de conhecimento sobre teorias psicológicas em geral. Embora o primeiro grupo de juízes estivesse mais próximo da visão leiga e o terceiro mais familiarizado com a literatura acadêmica, a semelhança entre as categoriza- ções produzidas pode ser tomada como indicativa da preponderância do empírico sobre o teórico. É interessante notar que os três grupos distinguiram entre aspectos relacionados ao micro e ao macrosocial, como o esquema de Baker e Jimerson (1992), e entre aspectos positivos e negativos do dinheiro, conforme tem sido salientado por muitos autores (Galbraith, 1987/1989; Katona, 1975; Marx, 1858/1984) e pelos ditados populares mais conhecidos acerca do dinheiro.

Comparando-se os resultados obtidos nesta validação às escalas anteriores, a estratégia de trabalho demonstrou ter sido satisfatória, abrindo a possibilidade de explorar espaços semânticos que ainda não haviam sido percebidos anteriormente, talvez por terem sido utilizadas bases teóricas restritas, desprezando-se o levantamento de dados empíricos preliminares. Outra vantagem é o fato de esta validação ter seguido os critérios psicométricos de modo mais rigoroso e ter sido realizada com amostra numerosa, abrangente e heterogênea. A heterogeneidade da amostra e o grande número de itens utilizados acarretaram maior variabilidade nos dados, fazendo com que o percentual de variância explicada pelos 82 itens na solução não tenha sido superior aos dos 
instrumentos anteriores. Entretanto, a estrutura fatorial encontrada foi clara, com apenas dois itens pertencendo a mais de um componente, e estável quando testada separadamente para homens e mulheres ou por meio de diferentes técnicas de extração e rotação. Três dos componentes encontrados apresentaram índices de fidedignidade bem superiores aos das escalas anteriores, quatro tiveram índices equivalentes, e apenas um, "Estabilidade", foi substancialmente mais fraco.

A compreensão teórica dos fatores hipotéticos havia levado à hipótese de uma estrutura lógica subjacente, implicando em um modelo com dimensões e níveis (ver Figura 1), que foi confirmado em termos gerais, sofrendo alguns ajustes. No primeiro nível do modelo, o fator hipotético Desigualdade Social foi confirmado, com agregação de apenas dois itens de outros fatores hipotéticos (Conflito e Prestígio), enquanto o fator hipotético Desenvolvimento SócioCultural foi dividido em dois componentes diferentes: "Progresso" e "Cultura". No segundo nível, os dois fatores hipotéticos (Dominação e Prestígio) juntaram-se em um mesmo componente, denominado "Poder". Aspectos pensados como negativos (“... cometer crimes impunemente”) não se diferenciaram daqueles que haviam sido pensados como positivos (“... reconhecimento social”). Os instrumentos anteriores que apresentaram um componente denominado como "Poder" indicaram significados diferentes para a palavra. Yamauchi e Templer (1982) e Furnham (1984) referiram-se ao uso do dinheiro para controlar e influenciar outras pessoas. Para Tang (1992), "Poder" foi relacionado à autonomia do indivíduo, enquanto o agrupamento de itens transmitindo a idéia de influência social foi denominado como "Respeito". Possivelmente, a idéia de poder social, quando relacionada a dinheiro, carrega uma ambigüidade que dificulta a discriminação entre aspectos positivos e negativos; ou, alternativamente, a separação entre estes aspectos está condicionada por padrões de julgamento moral a respeito dos quais não há consenso. Mais pesquisa parece ser necessária para clarear este fenômeno. No terceiro nível do modelo, o fator hipotético Desapego foi confirmado, mas os itens que constituíam Utilitarismo ("Nada nesta vida deve ser de graça", "Com dinheiro eu poderia ganhar mais dinheiro") dispersaram-se com baixas cargas fatoriais entre diversos componentes da solução. A definição deste fator hipotético enfatizava uma visão positiva, objetiva e racional, com a valorização do desejo de ter dinheiro como um fim em si mesmo. A falta de confirmação empírica pode prover ainda mais um argumento para os que criticam o modelo econômico de homem racional e utilitário (Belk, 1991; Etzioni, 1988; Tversky \& Kahneman, 1974). No quarto nível, o fator hipotético Conflito foi confirmado, absorvendo itens de Preocupação ("Dinheiro provoca neuroses", “... descontrole emocional”, “... lembra dívidas”). Estes itens tiveram cargas fatoriais extremamente baixas em todos os demais componentes, o que parece indicar diferenças entre a concepção leiga e a acadêmica, já que eles haviam alcançado $80 \%$ de concordância na análise de juízes. O fator hipotético Estabilidade também foi confirmado, embora com baixo nível de fidedignidade. No quinto nível, o fator hipotético Preocu- pação foi parcialmente confirmado. Ele foi renomeado para "Sofrimento", em função da forte carga emocional dos itens que se agregaram aqui. O fator hipotético Prazer foi confirmado, absorvendo alguns itens provenientes de outros fatores hipotéticos, principalmente de Estabilidade. Neste caso, os itens referiam-se a prazer relacionado à esfera familiar (“... ajuda a ter harmonia familiar”). O envolvimento do indivíduo com o grupo de pertencimento tem sido indicado como característica de culturas coletivistas, como seria o caso do Brasil para diversos autores (Kagitcibasi, 1997; Smith \& Bond, 1998; Triandis, 1995). Entretanto, mesmo em uma cultura como a norte-americana, freqüentemente caracterizada como individualista (Hofstede, 1994; Wheeler, Reis \& Bond, 1997), há indicativos de que a relação com a família é vista como o recurso mais importante para alcançar satisfação pessoal (Diener \& Fujita, 1995).

Considerando os ajustes impostos pelos resultados ao modelo hipotético, verificamos que a linha divisória vertical, traçada entre as dimensões positiva e negativa, foi negada duas vezes: No segundo nível, Dominação e Prestígio juntaram-se em um só componente e, no terceiro nível, Utilitarismo não foi confirmado, deixando Desapego sem contrapartida positiva. A disposição horizontal dos níveis sofreu ajustes mais sutis entre o nível dos relacionamentos e o da subjetividade individual, tanto na dimensão positiva quanto na negativa, mas que não chegaram a alterar o modelo hipotético. No aspecto positivo, o "Prazer" absorveu itens que haviam sido pensados como Estabilidade, um deslocamento no sentido do social para o individual, enquanto no aspecto negativo, ocorreu um movimento inverso. Em ambos os casos, os deslocamentos remetem à dificuldade de estabelecer uma linha divisória entre as esferas dos relacionamentos próximos e do intra-individual. Em função dos resultados, o modelo deve ser, então, reconfigurado como na Figura 2.

Entretanto, é necessário salientar que a possibilidade de dependência entre fatores do esquema hipotético foi explicitamente testada, e não foram encontradas correlações positivas ou negativas. Os componentes são empiricamente ortogonais. As relações que sugerimos entre eles devem ser pensadas apenas em termos lógicos de sua coerência teórica. A

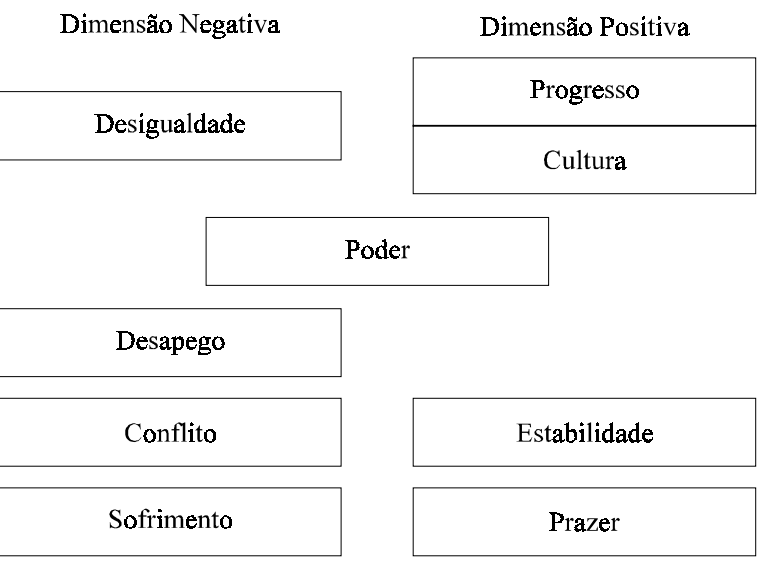

Figura 2 - Esquema fatorial ajustado pelos resultados 
idéia de níveis e dimensões, por outro lado, demonstrou ter utilidade como um racional para a compreensão a ampliação do espaço semântico do construto. Nossos resultados permitem sustentar que a idéia de que o dinheiro permeia todas as esferas da vida social não é apenas um produto da elaboração do pensamento acadêmico, mas também está presente nas associações simbólicas das pessoas em geral.

\section{Conclusão}

Neste trabalho, obteve-se alguns avanços em relação aos anteriormente realizados, no que diz respeito aos procedimentos para desenvolver e validar um instrumento de mensuração para o significado do dinheiro. Foi assegurada uma estratégia metodológica mais rigorosa; aspecto necessário a qualquer trabalho científico, mas que se torna uma exigência maior ao se tratar de um objeto de estudo tão suscetível a viés pessoal ou ideológico. A abrangência e heterogeneidade da amostra para a validação permitem sustentar que a estrutura encontrada é uma boa aproximação da realidade para a população brasileira escolarizada. No entanto, os baixos níveis de confiabilidade de alguns componentes sugerem a necessidade de trabalhos complementares. Duas soluções se apresentam: a primeira é tentar trabalhar novamente os componentes mais fracos, agregando novos itens para um novo teste empírico. Teoricamente, seria a solução mais interessante, com a desvantagem de tornar o instrumento mais longo e menos prático para utilização em outras pesquisas. A segunda é eliminar estes componentes e testar empiricamente o funcionamento de uma versão reduzida. A escolha entre as duas alternativas deve ser direcionada pelo objetivo de futuras pesquisas.

\section{Referências}

Allison, J. (1983). Behavioral economics. New York: Preger Publisher.

Babin, B.J., Darden, W.R. \& Griffin, M. (1994). Work and/or fun: Measuring hedonic and utilitarian shopping value. Journal of Consumer Research, 20(4), 644-656.

Baker, W.E. \& Jimerson, J.B. (1992). The sociology of money. American Behavioral Scientist, 35(6), 678-693.

Baron, R.M. \& Kenny, D.A. (1986). The moderator-mediator variable distinction in social psychological research: Conceptual, strategic, and statistical considerations. Journal of Personality and Social Psychology, 51, 1173-1182.

Belk, R.W. (1991). The ineluctable mysteries of possessions. Special issue: To have possessions: A handbook on ownership and property. Journal of Social Behavior \& Personality, 6(6), 1755.

Brandstaetter, E. \& Brandstaetter, H. (1996). What's money worth? Determinants of the subjective value of money. Journal of Economic Psychology, 17(4), 443-464.

Burgoyne, C.B. (1995). Financial organization and decision-making within western households. Journal of Economic Psychology, 16(3), 421-430.
Cowherd, D.M. \& Levine, D.I. (1992). Product quality and pay equity between lower-level employees and top management: An investigation of distributive justice theory. Special issueProcess and outcome-Perspectives on the distribution of rewards in organizations. Administrative Science Quarterly, 37(2), 302320.

Dalton, G. (1971). Economic theory and primitive society. American Anthropologist, 63, 1-25.

Diener, E. \& Fujita, F. (1995). Resources, personal strivings, and subjective well-being: A nomothetic and idiographic approach. Journal of Personality \& Social Psychology, 68(5), 926-935.

Dodd, N. (1997). A sociologia do dinheiro - Economia, razão e a sociedade contemporânea (W.M. Portinho, Trad.). Rio de Janeiro: Fundação Getúlio Vargas Editora. (Trabalho original publicado em 1994)

Doyle, K.O. (1992). Money and the behavioral sciences. American Behavioral Scientist, 35(6), 641-657.

Etzioni, A. (1988). Normative-afective factors: toward a new decision-making model. Journal of Economic Psychology, 9, 125150.

Freud, S. (1977). Charater and anal eroticism (J. Strachey, Trad.). Em A. Richards (Org.), On sexuality - Three essays on the theory of sexuality and other works (Vol. 7, pp. 205-215). Harmondsworth: Penguin Books. (Trabalho original publicado em 1908)

Freud, S. (1977). On transformations of instinct as exemplified in anal eroticism (J. Strachey, Trad.). Em A. Richards (Org.), On sexuality - Three essays on the theory of sexuality and other works (Vol. 7, pp. 293-320). Harmondsworth: Penguin Books. (Trabalho original publicado em 1917)

Furby, L. (1991). Understanding the psychology of possession and ownership: A personal memoir and an appraisal of our progress. Special issue: To have possessions: A handbook on ownership and property. Journal of Social Behavior \& Personality, 6(6), 457-463.

Furnham, A. (1983). Inflation and the estimated sizes of notes. Journal of Economic Psychology, 4(4), 349-352.

Furnham, A. (1984). Many sides of the coin: The psychology of money usage. Personality \& Individual Differences, 5(5), 501509.

Furnham, A. (1985). The perceived value of small coins. Journal of Social Psychology, 125(5), 571-575.

Furnham, A. \& Argyle, M. (1998). The psychology of money. London New York: Routledge.

Galbraith, J.K. (1989). O pensamento econômico em perspectiva Uma história crítica (C.M., Trad.). São Paulo: Livraria Pioneira Editora. (Trabalho original publicado em 1987)

Goldberg, H. \& Lewis, R. (1978). Money madness: The psychology of saving, spending, loving and hating money. London: Springwood.

Groenland, E.A.G., Bloem, J.G. \& Kuylen, A.A.A. (1996). Prototypicality and structure of the saving concept for consumers. Journal of Economic Psychology, 17, 691-708.

Hanley, A. \& Wilhelm, M.S. (1992). Compulsive buying: An exploration into self-esteem and money attitudes. Journal of Economic Psychology, 13(1), 5-18. 
Hofstede, G. (1994). Cultures and organizations: Software of the mind. London: HarperCollins Publishers.

Kagitcibasi, C. (1997). Individualism and collectivism. Em J.W. Berry, M.H. Segall \& C. Kagitcibasi (Orgs.), Handbook of crosscultural psychology - Social behavior and applications (2nd ed., Vol. 3, pp. 1-49). Boston: Allyn and Bacon.

Katona, G. (1975). Psychological economics. New York: Elsevier.

Kirchler, E. (1993). Spouses joint purchase decisions - Determinants of influence tactics for muddling through the process. Journal of Economic Psychology, 14(2), 405-438.

Kirchler, E. (1995). Studying economic decisions within private households - A critical- review and design for a couple experiences diary. Journal of Economic Psychology, 16(3), 393-419.

Kirchler, E. (1997). The burden of new taxes: Acceptance of taxes as a function of affectedness and egoistic versus altruistic orientation. Journal of Socio Economics, 26(4), 421-437.

Lamb, M.L. (1992). Theology and money: Rationality, religion, and economics. American Behavioral Scientist, 35(6), 735-755.

Lea, S.E.G., Tarpy, R.M. \& Webley, P. (1987). The individual in the economy: A textbook of economic psychology. Cambridge, England: Cambridge University Press.

Lea, S.E.G., Webley, P. \& Walker, C. (1995). Psychological-factors in consumer debt - Money management, economic socialization, and credit use. Journal of Economic Psychology, 16(3), 681-701.

Lewis, A., Webley, P. \& Furnham, A. (1995). The new economic mind. Hemel Hempstead: Harvester Wheatsheaf.

Livingstone, S. \& Lunt, P. (1993). Savers and borrowers: Strategies of personal financial management. Human Relations, 46(8), 963-985.

Lynn, R. (1991). The secret of the miracle economy. London: SAU.

Lynn, R. (1993). Sex differences in competitiveness and the valuation of money in twenty countries. Journal of Social Psychology, 133(4), 507-511.

Marx, K. (1984). Elementos fundamentales para la critica de la economia politica (Grundisse) (Volume 1, 13 ed.). (P. Scaron, Trad.) Madrid: Siglo XXI. (Trabalho original publicado em 1858)

Maslow, A.H. (1954). Motivation and personality. New York: Harper.

Medina, J.F., Saegert, J. \& Gresham, A. (1996). Comparison of Mexican-American and Anglo-American attitudes toward Money. Journal of Consumer Affairs, 30(1), 124-145.

Myerson, J. \& Green, L. (1995). Discounting of delayed rewards Models of individual choice. Journal of Experimental Analysis of Behavior, 64, 263-276.

Pahl, J. (1995). His money, her money - Recent research on financial organization in marriage. Journal of Economic Psychology, 16(3), 361-376.

Pasquali, L. (1996). Teoria e métodos de medida em ciências do comportamento. Brasília: UnB-INEP.
Pasquali, L. (1999). Testes referentes a construtos: teoria e modelo de construção. Em L. Pasquali (Org.), Instrumentos psicológicos: manual prático de elaboração. Brasília: LabPAM/IBAPP.

Politano, J. \& Lester, D. (1997). Self-destructiveness and credit card debt. Psychological Reports, 81(2), 634.

Porter, N.M. \& Garman, E.T. (1992). Money as part of a measure of financial well-being. American Behavioral Scientist, 35(6), 820-826.

Rubinstein, W.D. (1981). Survey report on money. Psychology Today, 5, 24-44.

Smith, P.B. \& Bond, M.H. (1998). Social psychology across cultures ( $2^{\mathrm{a}}$ ed.). London: Prentice Hall Europe.

Snelders, H.M., Hussein, G., Lea, S.E. \& Webley, P. (1992). The polymorphous concept of money. Journal of Economic Psychology, 13(1), 71-92.

Sorauf, F.K. (1992). Politics and money. American Behavioral Scientist, 35(6), 725-734.

Tabachnick, B.G. \& Fidell, L.S. (1996). Using multivariate statistics ( $3^{\mathrm{a}}$ ed.). New York: HarperCollins College Publishers.

Tang, T.L.P. (1992). The meaning of money revisited. Journal of Organizational Behavior, 13(2), 197-202.

Tang, T.L.P. \& Gilbert, P.R. (1995). Attitudes toward money as related to intrinsic and extrinsic job satisfaction, stress and workrelated attitudes. Personality and Individual Differences, 19(3), 327-332.

Thierry, H. (1992). Payment: Which meanings are rewarding? American Behavioral Scientist, 35(6), 694-707.

Triandis, H.C. (1995). Individualism \& collectivism. Boulder, CO, US: Westview Press.

Tversky, A. \& Kahneman, D. (1974). Judgment under uncertainty: Heuristics and biases - Biases in judgments reveal some heuristics of thinking under uncertainty. Science, 185, 1124-1131.

Wernimont, P.F. \& Fitzpatrick, S. (1972). The meaning of money. Journal of Applied Psychology, 56, 218-226.

Wheeler, L., Reis, H.T. \& Bond, M.H. (1997). Collectivism and individualism in everyday social life: The middle Kingdom and the Melting Pot. Em L.A. Peplau \& S.E. Taylor (Orgs.), Sociocultural perspectives in social psychology - current readings (pp. 297-313). New Jersey: Prentice Hall.

Yamauchi, H., Lynn, R. \& Rendell, I. (1994). Gender differences in work motivations and attitudes in Japan and Northern Ireland. Psychology: An International Journal of Psychologia in the Orient, 37(4), 195-198.

Yamauchi, K.T. \& Templer, D.I. (1982). The development of a money attitude scale. Journal of Personality Assessment, 46(5), 522-528.

Recebido em 15.06.1999 Primeira decisão editorial em 09.12.1999 Versão final em 18.01.2000 Aceito em 08.02.2000 


\section{Anexo}

\section{Escala de Significado do Dinheiro}

A seguir, você encontrará diversas afirmativas relacionadas a dinheiro. Estamos interessados em saber se você concorda ou não com o que cada frase afirma. Utilize a escala de cinco pontos que está colocada à direita de cada frase. Marque com um X o número que expressa a sua opinião. Os números da escala significam o seguinte:

$1=$ Discordo fortemente

2 = Discordo levemente

$3=$ Nem discordo nem concordo

4 = Concordo levemente

5 = Concordo fortemente

Marque apenas um número para cada frase e não deixe nenhuma frase sem resposta.

\begin{tabular}{|c|c|c|c|c|c|c|}
\hline & & $\begin{array}{l}\text { Discordo } \\
\text { fortemente }\end{array}$ & $\begin{array}{l}\text { Discordo } \\
\text { levemente }\end{array}$ & $\begin{array}{l}\text { Nem discordo } \\
\text { nem concordo }\end{array}$ & $\begin{array}{l}\text { Concordo } \\
\text { levemente }\end{array}$ & $\begin{array}{l}\text { Concordo } \\
\text { fortemente }\end{array}$ \\
\hline 1 & Dinheiro facilita a vida sexual das pessoas & 1 & 2 & 3 & 4 & 5 \\
\hline 2 & Quem tem dinheiro é valorizado socialmente & 1 & 2 & 3 & 4 & 5 \\
\hline 3 & Pensar em dinheiro me deixa deprimido & 1 & 2 & 3 & 4 & 5 \\
\hline 4 & Dinheiro lembra contrastes sociais & 1 & 2 & 3 & 4 & 5 \\
\hline 5 & Quem é rico pode impor sua opinião & 1 & 2 & 3 & 4 & 5 \\
\hline 6 & Dinheiro é uma coisa complicada para mim & 1 & 2 & 3 & 4 & 5 \\
\hline 7 & Dinheiro significa poder viajar & 1 & 2 & 3 & 4 & 5 \\
\hline 8 & Dinheiro é sinônimo de dor de cabeça & 1 & 2 & 3 & 4 & 5 \\
\hline 9 & Quem tem dinheiro deve empregá-lo no desenvolvimento do país & 1 & 2 & 3 & 4 & 5 \\
\hline 10 & Crianças ricas são ensinadas a evitar contato com crianças pobres & 1 & 2 & 3 & 4 & 5 \\
\hline 11 & Dinheiro provoca angústia & 1 & 2 & 3 & 4 & 5 \\
\hline 12 & Dinheiro é sinônimo de dominação & 1 & 2 & 3 & 4 & 5 \\
\hline 13 & 0 dinheiro facilita a convivência familiar & 1 & 2 & 3 & 4 & 5 \\
\hline 14 & Dinheiro traz esperança no futuro & 1 & 2 & 3 & 4 & 5 \\
\hline 15 & Ter dinheiro é ter poder & 1 & 2 & 3 & 4 & 5 \\
\hline 16 & Quero deixar minha família amparada financeiramente quando eu morrer & 1 & 2 & 3 & 4 & 5 \\
\hline 17 & O dinheiro provoca jogos de interesse & 1 & 2 & 3 & 4 & 5 \\
\hline 18 & Ficarei realizado quando atingir a situação que determinei para mim & 1 & 2 & 3 & 4 & 5 \\
\hline 19 & O dinheiro ajuda a evolução da humanidade & 1 & 2 & 3 & 4 & 5 \\
\hline 20 & Quem tem dinheiro é o primeiro a ser atendido em qualquer lugar & 1 & 2 & 3 & 4 & 5 \\
\hline 21 & Tenho medo de gastar mais do que posso & 1 & 2 & 3 & 4 & 5 \\
\hline 22 & Dinheiro traz reconhecimento social & 1 & 2 & 3 & 4 & 5 \\
\hline 23 & Dinheiro gera desarmonia nas famílias & 1 & 2 & 3 & 4 & 5 \\
\hline 24 & 0 dinheiro torna as relações amorosas mais agradáveis & 1 & 2 & 3 & 4 & 5 \\
\hline 25 & Dinheiro gera ingratidão & 1 & 2 & 3 & 4 & 5 \\
\hline 26 & Sou desapegado das coisas materiais & 1 & 2 & 3 & 4 & 5 \\
\hline 27 & Pessoas negras e pobres são vistas como perigosas & 1 & 2 & 3 & 4 & 5 \\
\hline 28 & Quem tem dinheiro pode cometer crimes impunemente & 1 & 2 & 3 & 4 & 5 \\
\hline 29 & Ajudar quem precisa é melhor que guardar dinheiro & 1 & 2 & 3 & 4 & 5 \\
\hline 30 & Dinheiro provoca casamentos por interesse & 1 & 2 & 3 & 4 & 5 \\
\hline 31 & Gosto de ajudar amigos em dificuldades financeiras & 1 & 2 & 3 & 4 & 5 \\
\hline 32 & Quem tem dinheiro passa por cima das normas estabelecidas & 1 & 2 & 3 & 4 & 5 \\
\hline 33 & Quando compro coisas novas esqueço meus problemas & 1 & 2 & 3 & 4 & 5 \\
\hline 34 & Crianças ricas são educadas para mandar & 1 & 2 & 3 & 4 & 5 \\
\hline 35 & A cho importante ter seguro de vida & 1 & 2 & 3 & 4 & 5 \\
\hline 36 & Dinheiro causa assassinatos & 1 & 2 & 3 & 4 & 5 \\
\hline 37 & Eu investiria dinheiro em inovações tecnológicas & 1 & 2 & 3 & 4 & 5 \\
\hline 38 & Dinheiro significa status social & 1 & 2 & 3 & 4 & 5 \\
\hline 39 & Dinheiro provoca frustrações & 1 & 2 & 3 & 4 & 5 \\
\hline 40 & Quem tem fé sabe que precisa fazer caridade & 1 & 2 & 3 & 4 & 5 \\
\hline 41 & Pessoas pobres são impedidas de ir a lugares freqüentados por gente rica & 1 & 2 & 3 & 4 & 5 \\
\hline 42 & Dinheiro atrai felicidade & 1 & 2 & 3 & 4 & 5 \\
\hline 43 & Dinheiro atrai inveja & 1 & 2 & 3 & 4 & 5 \\
\hline 44 & Eu investiria dinheiro em eventos culturais & 1 & 2 & 3 & 4 & 5 \\
\hline & Dinheiro provoca neuroses & 1 & 2 & 3 & 4 & 5 \\
\hline & Dinheiro gera progresso & 1 & 2 & 3 & 4 & 5 \\
\hline
\end{tabular}




\begin{tabular}{|c|c|c|c|c|c|}
\hline & $\begin{array}{l}\text { Discordo } \\
\text { fortemente }\end{array}$ & $\begin{array}{l}\text { Discordo } \\
\text { levemente }\end{array}$ & $\begin{array}{l}\text { Nem discordo } \\
\text { nem concordo }\end{array}$ & $\begin{array}{l}\text { Concordo } \\
\text { levemente }\end{array}$ & $\begin{array}{l}\text { Concordo } \\
\text { fortemente }\end{array}$ \\
\hline 47 Dinheiro ajuda a ter harmonia familiar & 1 & 2 & 3 & 4 & 5 \\
\hline 48 Dinheiro provoca ilusões & 1 & 2 & 3 & 4 & 5 \\
\hline 49 Quem tem dinheiro tem autoridade sobre os outros & 1 & 2 & 3 & 4 & 5 \\
\hline 50 É dever de todas as pessoas dividirem o que têm & 1 & 2 & 3 & 4 & 5 \\
\hline 51 Dinheiro provoca traições & 1 & 2 & 3 & 4 & 5 \\
\hline 520 dinheiro ajuda as pessoas a gostarem mais de si mesmas & 1 & 2 & 3 & 4 & 5 \\
\hline 53 Quem tem dinheiro se livra de entrar em filas & 1 & 2 & 3 & 4 & 5 \\
\hline 54 Dinheiro significa prazer & 1 & 2 & 3 & 4 & 5 \\
\hline 55 As pessoas deveriam dar menos importância a bens materiais & 1 & 2 & 3 & 4 & 5 \\
\hline 56 Com dinheiro eu investiria em pesquisas científicas & 1 & 2 & 3 & 4 & 5 \\
\hline 57 Dinheiro provoca descontrole emocional & 1 & 2 & 3 & 4 & 5 \\
\hline 580 dinheiro torna as pessoas oportunistas & 1 & 2 & 3 & 4 & 5 \\
\hline 59 Quem tem dinheiro é o centro das atenções & 1 & 2 & 3 & 4 & 5 \\
\hline 60 As pessoas submetem-se a quem tem dinheiro & 1 & 2 & 3 & 4 & 5 \\
\hline 61 Tenho pesadelos por causa de dinheiro & 1 & 2 & 3 & 4 & 5 \\
\hline 62 Dinheiro ajuda a ser feliz & 1 & 2 & 3 & 4 & 5 \\
\hline 63 Dinheiro provoca desavenças com parentes & 1 & 2 & 3 & 4 & 5 \\
\hline 64 Dinheiro possibilita ascensão social & 1 & 2 & 3 & 4 & 5 \\
\hline 650 dinheiro representa a busca de felicidade & 1 & 2 & 3 & 4 & 5 \\
\hline 66 Eu uso o meu dinheiro para ficar contente & 1 & 2 & 3 & 4 & 5 \\
\hline 67 Dinheiro garante prosperidade para a sociedade & 1 & 2 & 3 & 4 & 5 \\
\hline 68 Quem é rico impõe sua personalidade & 1 & 2 & 3 & 4 & 5 \\
\hline 69 A classe pobre é excluída dos direitos sociais & 1 & 2 & 3 & 4 & 5 \\
\hline 700 dinheiro facilita a vida da humanidade & 1 & 2 & 3 & 4 & 5 \\
\hline 71 É preciso ter dinheiro para ter prestígio & 1 & 2 & 3 & 4 & 5 \\
\hline 72 Dinheiro atrai falsos amigos & 1 & 2 & 3 & 4 & 5 \\
\hline 73 A cho importante fazer convênios de saúde & 1 & 2 & 3 & 4 & 5 \\
\hline 74 Recompensas espirituais são mais importantes que dinheiro & 1 & 2 & 3 & 4 & 5 \\
\hline 75 Com dinheiro eu patrocinaria o desenvolvimento das artes & 1 & 2 & 3 & 4 & 5 \\
\hline 76 Dinheiro gera desconfiança entre pessoas & 1 & 2 & 3 & 4 & 5 \\
\hline 77 Os pais devem ensinar os filhos a serem generosos & 1 & 2 & 3 & 4 & 5 \\
\hline 78 Dinheiro lembra dívidas & 1 & 2 & 3 & 4 & 5 \\
\hline 790 dinheiro constrói um mundo melhor & 1 & 2 & 3 & 4 & 5 \\
\hline 80 Basta crer em Deus para ter as necessidades atendidas & 1 & 2 & 3 & 4 & 5 \\
\hline 81 As pessoas tentam agradar quem tem dinheiro & 1 & 2 & 3 & 4 & 5 \\
\hline 82 Dinheiro resolve problemas sociais & 1 & 2 & 3 & 4 & 5 \\
\hline
\end{tabular}

Normas para Apuração de Resultados

\begin{tabular}{|c|c|c|}
\hline Componentes & Itens & No de itens \\
\hline 1 Prazer & $1,7,13,14,24,33,42,47,52,54,62,64,65,66$ & 14 \\
\hline 2 Poder & $5,12,15,20,22,28,32,34,38,49,53,59,60,68,69,71,81$ & 17 \\
\hline 3 Conflito & $8,23,25,30,36,43,45,48,51,57,58,63,72,76,78$ & 15 \\
\hline 4 Desapego & $26,29,31,40,50,55,74,77,80$ & 9 \\
\hline 5 Sofrimento & $3,6,11,39,61$ & 5 \\
\hline 6 Progresso & $19,46,67,70,79,82$ & 6 \\
\hline 7 Desigual dade & $2,4,10,17,27,41$ & 6 \\
\hline 8 Cultura & $9,37,44,56,75$ & 5 \\
\hline 9 Estabilidade & $16,18,21,35,73$ & 5 \\
\hline
\end{tabular}

